\title{
Comparative Study of Injection Systems in Vapor Phase in the Remediation of Soils Contaminated by Diesel
}

Rayana Hozana Bezerril', Tamyris Thaise Costa de Souza ${ }^{2}$, Adriana Margarida Zanbotto Ramalho³, Djalma Ribeiro da Silva ${ }^{1,4 *}$, Tereza Neuma de Castro Dantas ${ }^{2,4}$

${ }^{1}$ Petroleum Engineering Post-Graduation Program, Federal University of Rio Grande do Norte, UFRN, Brazil ${ }^{2}$ Chemical Engineering Post-Graduation Program, Federal University of Rio Grande do Norte, UFRN, Brazil

${ }^{3}$ National Program of Post-Doctoral - PNPD/CAPES, Federal University of Rio Grande do Norte, UFRN, Brazil

${ }^{4}$ Chemistry Post-Graduation Program, Institute of Chemistry, Federal University of Rio Grande do Norte, UFRN, Brazil

\begin{abstract}
Gasoline and diesel leaks in underground storage tanks contaminate soils with petroleum hydrocarbons. Various techniques using surfactants have been proposed to remedy this type of contamination. This study presents the application of different systems containing surfactants in vapor phase. It compares the removal efficiencies of diesel contaminated soils using vapor injection systems: surfactant water solutions, micro-emulsions, and nano-emulsions. The surfactant used in the experiments was ethoxylated alcohol UNTL-90 in aqueous solution, in nano-emulsion, and micro-emulsion systems. Among the systems investigated, the nano-emulsion showed the highest removal efficiency $(88 \%)$, being environmentally friendly and technically feasible with a system that has a lower content of active matter.
\end{abstract}

Keywords: Surfactants; Ethoxylated alcohol; Contaminated soils; Diesel

\section{Introduction}

Environmental accidents are common throughout the stages of the oil production process, as well as during the production and distribution of its derivatives. This type of contamination affects soils and underground water with toxic and/or carcinogenic substances such as: BTEX (benzene, toluene, ethylbenzene, and xylenes), polycyclic aromatic hydrocarbons (PAHs) and total petroleum hydrocarbons (TPH) $[1,2]$. The soil in contact with hydrocarbons easily absorbs contaminants due to its low solubility in water, which creates difficulties in the treatment of soil [3].

For this type of contamination there are treatment technologies already consolidated, such as soil vapor extraction (SVE), airsparging, biosparging, land farming, bio piles, bioventing, low-temperature thermal desorption, in situ groundwater bioremediation, dualphase extraction, monitored natural attenuation, enhanced aerobic bioremediation, and chemical oxidation [4]. Among this range of techniques already established for remediation, bioremediation has been used as a solution to the degradation of petroleum hydrocarbons in soil and in contaminated water [5-10]. One can also highlight the studies developed with the use of bio-surfactants, which show great efficiencies in the remediation of oil contaminated soils [11].

In this context, innovative technologies such as radio frequency heating, co-solvents, surfactants, and soil washing have shown satisfactory results, considering viability for use in typical leaking in underground storage tanks sites [4]. The use of surfactant in the treatment of soil contaminated by hydrocarbons occurs due to its amphiphilic properties, affinity for oil and water, which can reduce surface and interfacial tension and form aggregates (micelles). The reduction in interfacial tension can facilitate the transport of organic contaminants from the soil through a washing solution [12-14]. Most studies that use this type of system have shown satisfactory result in the removal of organic compounds from soil and groundwater [7,8,15-19]. Unlike other research that performed the washing of the soil with surfactant solutions [20-27], this study aims to inject the steam of micro-emulsions, surfactant solutions and Nano-emulsions in the remediation of soils contaminated by diesel. Although all these systems have a surfactant, they differ in their compositions and properties becoming a potential alternative to the remediation of soils contaminated with diesel fuel.

Surfactant solutions have homogeneous appearance and they are composed only by water and surfactant that form micelles in aqueous solution, spontaneously, from a certain critical concentration of micelle (CMC). The micro-emulsions consist of an aqueous phase, an oil phase, a surfactant and a co-surfactant. They are isotropic and thermodynamically stable systems [12,28-30]. The Nano-emulsion is made up of the same components of the micro-emulsion, but differs in the percentages of the components of the micro-emulsion, because it uses a smaller amount of surfactant and co-surfactant, and does not show thermodynamic stability. Their advantages over the use of microemulsions are associated with the need for a reduced amount of active matter and a smaller diameter of particles [31,32]. The methodology used in this study is also different when compared with other studies using soil washing with surfactant-containing systems [20,23,2527]. The principle steam injection applied in enhanced oil recovery was used in remediation of contaminated soils, aiming to combine highest temperature with the power of solubilization and miscibility of the systems, with the objective of increasing the mobilization and solubilization of hydrocarbons through the decrease of interfacial tension in the soil/organic phase and in water/organic phase interfaces, increasing the efficiency of the desorption of diesel in the soil offering an innovative method of soil remediation [33-34].

*Corresponding author: Djalma Ribeiro da Silva, Federal University of Rio Grande do Norte, UFRN, Brazil, Tel: +336-334-7787; E-mail: djalmarib@gmail.com

Received July 03, 2014; Accepted August 11, 2014; Published August 18, 2014

Citation: Bezerril RH, de Souza TTC, Ramalho AMZ, da Silva DR, Dantas TNC (2014) Comparative Study of Injection Systems in Vapor Phase in the Remediation of Soils Contaminated by Diesel. J Pet Environ Biotechnol 5: 184 doi:10.4172/2157-7463.1000184

Copyright: (c) 2014 Bezerril RH, et al. This is an open-access article distributed under the terms of the Creative Commons Attribution License, which permits unrestricted use, distribution, and reproduction in any medium, provided the original author and source are credited. 


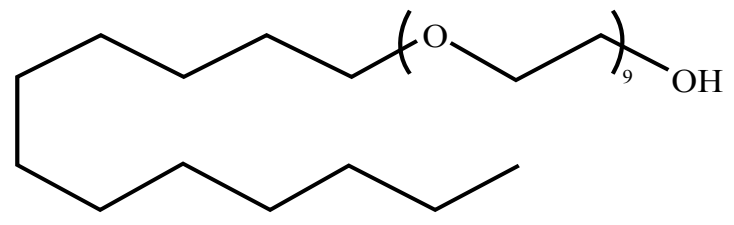

Figure 1: Molecule of UNTL-90 [35]

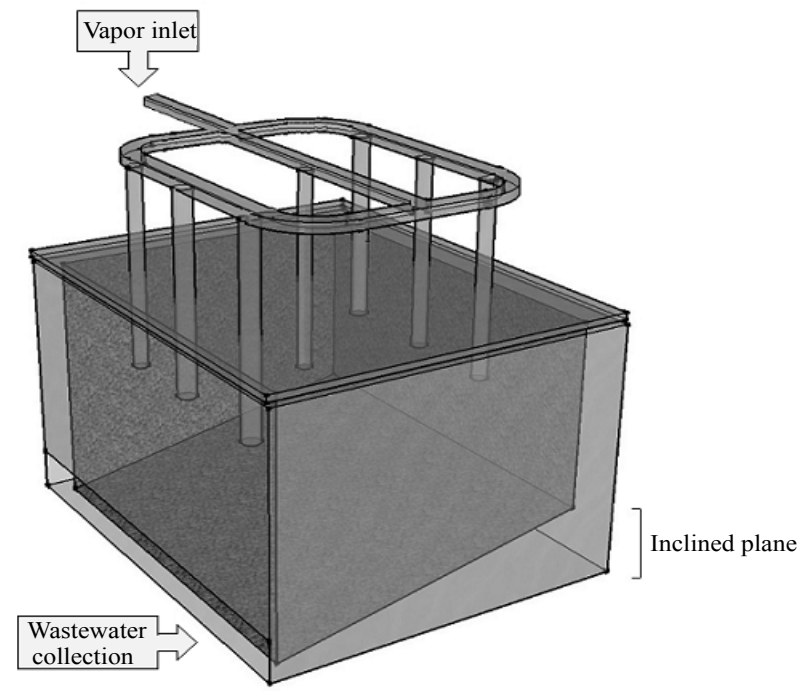

Figure 2: Steam injection system for the use in the treatment of soil contaminated with diesel.

\section{Materials and Methods}

\section{Materials}

The surfactant used in obtaining the injection systems, the UNTL90 , is a non-ionic type obtained from the reaction between lauryl alcohol and ethylene oxide. In the reaction, the lipophilic character comes from the molecule of the starting alcohol, and hydrophilic from an ethylene oxide chain. The symbol L-90 indicates the degree of ethoxylation which influences the hydrophilicity of the molecule and, thus, its solubility, wettability, and detergency, allowing this product to be used with emulsifying and solubilizing detergent [35,36]. Figure 1 shows the UNTL-90 molecule.

In the preparation of the surfactant solution, micro-emulsion, Nano-emulsion, some and other reagents such as water, n-butanol (Vetec), and kerosene (Petro bras) were used. As the research objective was to remove the diesel from a contaminated soil, a system with a lower percentage of oil phases in the aqueous-rich phase from the phase diagram was selected. Butanol was used as a co-surfactant because it stabilizes the micro-emulsion and improves the solubilization of surfactant.

The soil used for the experiments was collected in a non-saturated Dunes Coastal Highway, located within the city limits of Natal, capital of Rio Grande do Norte, Brazil. The hydraulic conductivity $(\mathrm{K})$ is $2.2 \times 10^{-4} \mathrm{~m} / \mathrm{s}$ indicating a high permeability [37]. This soil sample had characteristics of sand, with grain sizes divided as $8.9 \%$ coarse sand, $88.33 \%$ medium, and $2.77 \%$ fine sand. Initially, the soil sample was contaminated with $5000 \mathrm{mg}$ TPH/Kg dry soil (diesel S-500, Petro bras).

\section{Methods}

In this step, the ways preparation and utilization of the systems are described.

Injection system: For the treatment of soil contaminated by diesel, a system was employed in a bench scale Figure 2 which consists of a cube made of laminated glass, which supports a temperature of $200^{\circ} \mathrm{C}$, and with a capacity of $1 \mathrm{~kg}$ of soil. In the Injection System, volumes of 500; 1,750 ; and $3,000 \mathrm{~mL}$ of vaporized systems were obtained. The solutions were transferred by an injector tube connected to 7 injection wells. The efficiencies of treatment by each injected fluid were compared.

Characterization of the system: The systems used as injection fluid were characterized by the $\mathrm{pH}$, conductivity, surface tension, and particle size and beyond the temperature of the vapor in contact with the ground. The steam condensate was obtained, without going through the injection system, to analyze the effect of condensation of the soil column. A pH meter (TEC-3P-MP, Tecnal) and a conductive meter (DM31, Digimed) were used to measure the conductivity at $25^{\circ} \mathrm{C}$.

Measurements of particle size were determined for the solution of the surfactant's critical micelle concentration, micro-emulsion, and Nano-emulsion using a Nano-trac (NPA 252, Micro-trac). The surface tension tests were performed with the Tension meter Sensa Dyne (QC6000). All measurements were performed at $25^{\circ} \mathrm{C}$.

Injection fluids: Water was the first fluid injected into the system to remove diesel because it serves as a blank to check the influence of the surfactants.

Initially, for the surfactant injection solutions tests, the critical micelle concentration (CMC) of UNTL90 in water was determined. The graphic of surface tension versus surfactant concentration was constructed, from a concentrated surfactant solution $(20 \mathrm{~g} / \mathrm{L})$, to dilute solutions with surface tensions close to the one of water $(72$ dynes. $\mathrm{cm}$ $\left.{ }^{1}\right)$. The surface tension measurements were determined using a tension meter (QC6000, Sensa Dyne Instruments) at $25^{\circ} \mathrm{C}$. The concentrations of surfactant solutions used were chosen based on the CMC value.

The micro-emulsion system used in this study came from a point on the pseudo-ternary diagram shown in Figure 3. The Nano-emulsified system was obtained from the chosen point of micro-emulsion following the methodology described by Souza [38]. The methodology aimed to

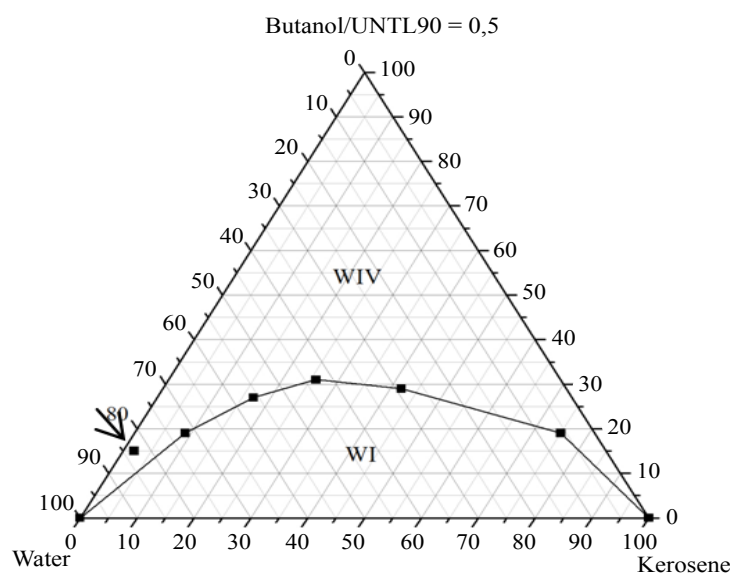

Figure 3: Diagram of pseudo ternary phase for system: UNTL90 (Surfactant) + n-butanol (co-surfactant) +kerosene + water at $25^{\circ} \mathrm{C}$ [39]. 


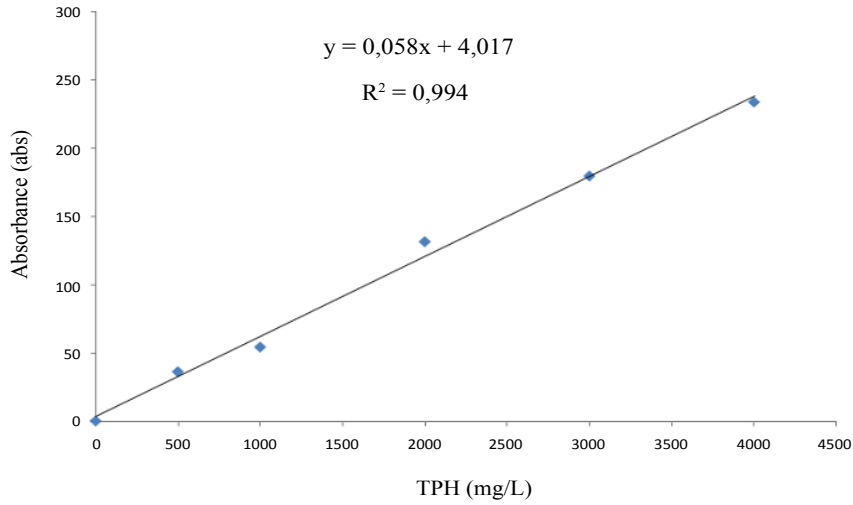

Figure 4: Straight line equation and linearity coefficient.

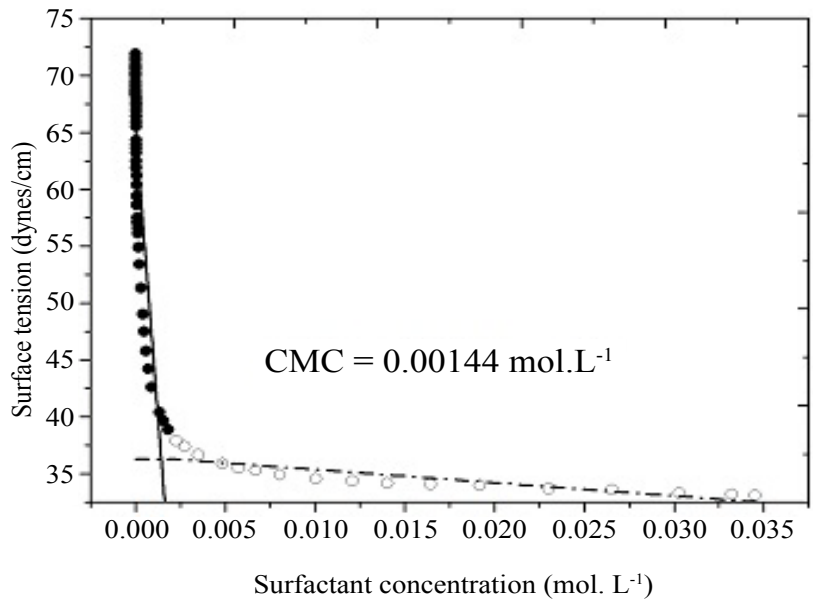

Figure 5: Determination of critical micelle concentration (CMC) for UNTL90 surfactant in the aqueous phase at $25^{\circ} \mathrm{C}$.

reduce the percentage of co-surfactant/surfactant while maintaining a clear and stable system using the surface tension as a parameter for determining the concentration of active matter.

\section{Methodology to Quantify the Diesel in Soil}

For the quantification of diesel in the soil, a $25 \mathrm{~g}$ sample of the soil mixed with $50 \mathrm{ml}$ of hexane were placed in a conical flask $(100 \mathrm{~mL})$ under mechanical agitation for 15 minutes in ultrasound Transonic (T460-Elma). After the extraction, the samples were filtered over $1 \mathrm{~g}$ of chromatographic silica to remove traces of water. The TPH (Total Petroleum Hydrocarbons) was used to assess the amount of diesel into the soil, the parameter was determined by infrared (HATR-T2 - Infracal TOG/TPH - Wilks Enterprise) based on the absorbance of the $\mathrm{CH}$ bond of hydrocarbons present in the extract to quantify the diesel [40]. The efficiency of treatment of the soil samples is calculated according to equation:

$\mathrm{ET} \%=\left[\left(\mathrm{CI}_{\mathrm{TPH}}-\mathrm{CF}_{\mathrm{TPH}}\right) / \mathrm{CI}_{\mathrm{TPH}}\right] \times 100$

Where:

ET\%: Efficiency of treatment

$\mathrm{CI}_{\mathrm{TPH}}$ : Initial Concentration of TPH

$\mathrm{CF}_{\mathrm{TPH}}$ : Final Concentration of TPH
For the preparation of the test standards, $0 ; 500 ; 1,000 ; 2,000 ; 3,000$; and $4,000 \mathrm{mg} / \mathrm{L}$ diesel S-500 were used, the straight line equation is shown in Figure 4. Linear coefficient $\left(\mathrm{R}^{2}\right)$ of this equation was 0.994 .

The Infracal TOG/TPH (HATR-T2) showed exactitude between $6-8 \%$ and precision of $\pm 1 \%$ in the analysis of a sample of known concentration of diesel in hexane $(3,102 \mathrm{mg} / \mathrm{L})$, repeated five times.

When the samples analyzed exceeded the maximum limit of the calibration curve, some dilutions were made of 1:1. Subsequently, the values were converted to $\mathrm{mg} / \mathrm{kg}$.

\section{Results and Discussion}

\section{Injection fluids}

The concentrations of surfactant solutions injected into the system were chosen based on the value of the CMC obtained. Figure 5 shows the graph of surface tension versus surfactant concentration, in which the value of the CMC is highlighted. The concentrations of the surfactant solutions were equal to the CMC ones, $60 \%$ above and $60 \%$ below this value. The molar mass of UNTL-90 corresponded to $582{\mathrm{~g} . \mathrm{mol}^{-1}}^{-1}$; a solution on CMC of this surfactant has a 0.00144 mol.L $\mathrm{L}^{-1}$ concentration, which corresponds to 0.838 g. $\mathrm{L}^{-1}$. To prepare the $60 \%$ solution below the CMC 0.335 g. $\mathrm{L}^{-1}$ or 0.00057 mol.L $\mathrm{L}^{-1}$ were used as concentration, while the $60 \%$ solution of CMC used concentrations above 1.340 g. $\mathrm{L}^{-1}$ or $0.00230 \mathrm{~mol} . \mathrm{L}^{-1}$.

The concentration of the surfactant took into account the arrangement of surfactant molecules in the system. For the concentration smaller than the CMC values, the surfactant was in the form of monomers. Concentrations equal to or higher than the CMC ones lead to the formation of aggregates, since a greater concentration of surfactant increased the number of aggregates formed.

The point of micro-emulsion chosen had the following composition: $83 \%$ water, $15 \%$ C- Co-surfactant/T-Surfactant, $\mathrm{C} / \mathrm{T}=0.5$, and $2 \%$ Kerosene, and is located in a region of the micro-emulsion rich in water with smaller amounts of active matter.

The preparation of the Nano-emulsion surface tension parameter, used for determining the optimal dilution of the micro-emulsion, was based on a value of low surface tension for a minimum concentration of surfactant. In Figure 6, surface tension versus surfactant concentration graph shows a steeper increase in concentration of surface tension to

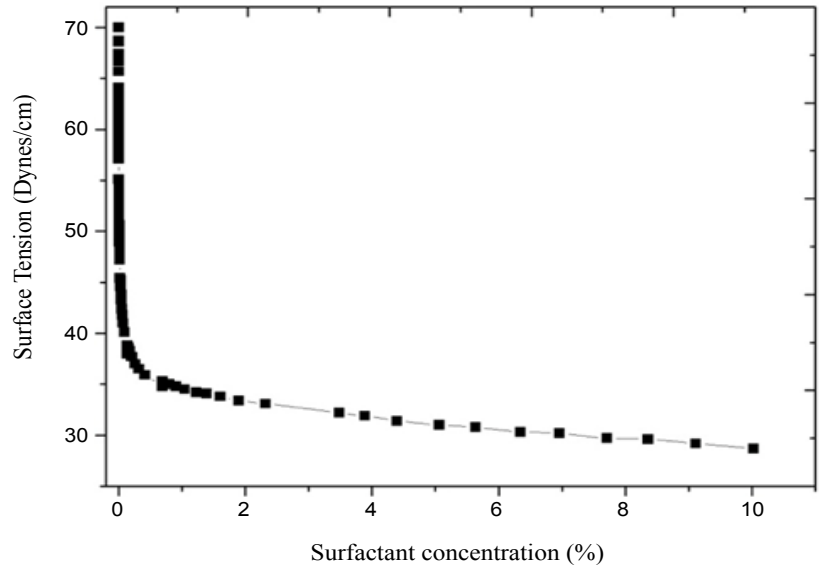

Figure 6: Data surface tension $\mathrm{x}$ surfactant concentration to obtain the Nano emulsion. 
Citation: Bezerril RH, de Souza TTC, Ramalho AMZ, da Silva DR, Dantas TNC (2014) Comparative Study of Injection Systems in Vapor Phase in the Remediation of Soils Contaminated by Diesel. J Pet Environ Biotechnol 5: 184. doi:10.4172/2157-7463.100018

Page 4 of 6

\begin{tabular}{|c|c|c|c|c|c|c|}
\hline \multirow[b]{2}{*}{ Fluids Injection } & \multirow[b]{2}{*}{$\mathrm{pH}$} & \multirow{2}{*}{$\begin{array}{l}\text { Conductivity }(\mu S / \\
\mathrm{cm})\end{array}$} & \multirow[b]{2}{*}{$\begin{array}{l}\text { Particle Diameter } \\
\text { (nm) }\end{array}$} & \multirow[b]{2}{*}{$\begin{array}{l}\text { Steam temperature } \\
\left({ }^{\circ} \mathrm{C}\right)\end{array}$} & \multicolumn{2}{|c|}{ Surface tension (Dynes.cm ${ }^{-1}$ ) } \\
\hline & & & & & $\begin{array}{l}\text { Liquid Systems } \\
\left(25^{\circ} \mathrm{C}\right)\end{array}$ & $\begin{array}{l}\text { White steam condensate } \\
\qquad\left(25^{\circ} \mathrm{C}\right)\end{array}$ \\
\hline Water & 5,55 & 147,84 & - & 98 & - & - \\
\hline ST $60 \%<$ CMC & 6,06 & 3,33 & - & 92 & 39,5 & 39,8 \\
\hline $\mathrm{ST}$ in $\mathrm{CMC}$ & 6,41 & 6,30 & 6,5 & 95 & 34,8 & 38,0 \\
\hline ST $60 \%>C M C$ & 6,13 & 6,97 & 1,0 & 97 & 34,8 & 35,2 \\
\hline Micro emulsion & 5,33 & 113,6 & 6,7 & 95 & 28,7 & 37,2 \\
\hline Nano emulsion & 5,50 & 16,1 & 1,1 & 96 & 33,5 & 33,8 \\
\hline
\end{tabular}

${ }^{*} \mathrm{ST}=$ Surfactant solution.

Table 1: Characterization of different injection systems studied.

\begin{tabular}{|c|c|c|c|c|c|c|}
\hline \multirow{3}{*}{$\begin{array}{l}\text { Injection volume } \\
\qquad(\mathrm{mL})\end{array}$} & \multicolumn{6}{|c|}{ INJECTION SYSTEMS } \\
\hline & \multirow{2}{*}{ Water vapor } & \multicolumn{3}{|c|}{ Surfactant solutions } & \multirow{2}{*}{ Micro emulsion } & \multirow{2}{*}{ Nano emulsion } \\
\hline & & $60 \%<\mathrm{cmc}$ & cmc & $60 \%>c \mathrm{mc}$ & & \\
\hline 500 & $29 \%$ & $13 \%$ & $21 \%$ & $23 \%$ & $60 \%$ & $67 \%$ \\
\hline 1,750 & $32 \%$ & $28 \%$ & $58 \%$ & $60 \%$ & $67 \%$ & $85 \%$ \\
\hline 3,000 & $66 \%$ & $59 \%$ & $67 \%$ & $67 \%$ & $86 \%$ & $88 \%$ \\
\hline
\end{tabular}

Table 2: Removal efficiency of diesel soil as a function of injection volumes using different systems of steam.

less than $1 \%$ surfactant. Therefore, the percentage of surfactant in the Nano-emulsion was reduced to a dilution of 10 times contained in the micro-emulsion. Thus, other components also changed their percentage in the Nano-emulsion percentage leading to the following composition: $1.0 \%$ UNTL90, $0.5 \%$ n-butanol, $0.2 \%$ kerosene, and $98.3 \%$ aqueous phase.

\section{Characterization of injection systems}

A Table 1 shows the results of the characterization of the studied systems used in the injection step.

The results of Table 1 show that the conductivity values indicate the presence and mobility of ionic species in each system, as well as their degree of stability. The conductivity of water $(147.84 \mu \mathrm{S} / \mathrm{cm})$ is related to its acidity ( $\mathrm{pH}=5.55)$. In the surfactant solution, the increase in $\mathrm{pH}$ (6.06 to 6.41) was due to the protonation of light oxygen's present in the molecule UNTL90, decreasing concentration of $\mathrm{H}^{+}$of the medium and, consequently reducing concentrations ( 3.30 to $6.97 \mu \mathrm{S} / \mathrm{cm}$ ). However, micro-emulsion and Nano-emulsion systems repeated a decrease in $\mathrm{pH}$ (5.33 and 5.50). This happened because of the presence of butanol, which has a hydroxyl group, forming hydrogen bonds with the oxygen of UNTL90, and the $\mathrm{H}^{+}$ions from the "environment" are no longer used for protonation of the heteroatoms of the surfactant molecule.

Temperature values of the six vapors injected fluids ranged from $92-98^{\circ} \mathrm{C}$. Thermal effects are important in the discussion of remediation efficiency. The results for the particle diameter vary in a range from 1.1 to $6.7 \mathrm{~nm}$, showing the ease of leaching in each fuel injection system and its contribution to soil removal efficiency of diesel engines.

Comparing the results of surface tension fluid injection prepared at room temperature with the ones of the condensed steam reveals that there were no significant losses in property with the change in physical state.

\section{Influence of injection volumes of the systems in removal} efficiency

Table 2 shows the percentage of oil removal from diesel obtained with different solution volumes $(500 ; 1,750 ; 3,000 \mathrm{~mL})$ of the injection systems.

Looking at injection volumes Table 2, an increase in removal efficiency can be observed when the volume is increased, regard less of the injected system, featuring a forced removal by drag.

Comparing the results of water injection with the injection of surfactant solutions below the CMC (where there are only monomers) it was observed that, for that amount of surfactant, the drag had an efficiency below the water injection, since the drag doesn't happen due to the influence of surface tension, but because of the influence of water temperature $\left(98^{\circ} \mathrm{C}\right)$ in the diesel displacement. Furthermore, the monomers possibly contribute to a reduction of vapor pressure in this solution, driven by Raoult's law and, hence, reduce the system's temperature to $92^{\circ} \mathrm{C}$ and the oil removal.

For the solutions injected with surfactant with volumes 500 to $1,750 \mathrm{~mL}$, it was noted that the removal of the diesel increased with an increase in surfactant concentration in the medium. Nevertheless, when considering the volume of $3,000 \mathrm{~mL}$, efficiencies with similar values was observed regard less of the concentrations, indicating the existence of a removal limit, after soil saturation. Yet, analyzing surfactant concentration below the CMC, the surfactant in the monomeric form cannot encapsulate the diesel, which might explain its low efficiency compared to micellar systems. When injecting surfactant solutions with concentrations in the $\mathrm{CMC}$, there is a presence of micelles that can encapsulate the diesel, and drag it to the fluid outlet of the injection system. Thus, the concentration values below the CMC present lower efficiency compared to the concentration values above it, as well as when compared with injection of water. This behavior is observed for the three injection volumes.

Analyzing the behavior of micro-emulsion and Nano-emulsion based systems; one can observe that these had higher removal efficiencies than the water and surfactant solutions ones, in the three volumes injected. Comparing only the set wo systems, the percentages of removal are similar, especially for the volume of $3,000 \mathrm{~mL}$, also due to drag. However, it is important to highlight the greater efficiency of these systems compared to water vapor and surfactant ones. Nanoemulsion and micro-emulsion systems have structures that favor the removal of the diesel by interactions, decreasing the surface tension. These systems possess high power solubility, since they have an oil phase that is compatible with the contaminant. Thus, the application of micro-emulsion and Nano-emulsion systems increases the percentage 
Citation: Bezerril RH, de Souza TTC, Ramalho AMZ, da Silva DR, Dantas TNC (2014) Comparative Study of Injection Systems in Vapor Phase in the Remediation of Soils Contaminated by Diesel. J Pet Environ Biotechnol 5: 184. doi:10.4172/2157-7463.100018

of diesel removal significantly. From these results, the parameter of surface tension associated with the presence of the oil phase (kerosene present in these systems) is responsible for the increased removal efficiency, as the continuous phase of the micro and Nano emulsion systems can improve the penetration of the diesel, making the drag and improving the efficiency of displacement.

The same results do not happen in surfactant solutions due to a lack of an oil phase, although they have low surface tensions. Surfactant solution efficiencies are compared to the water one, which has high surface tension, prioritizing the drag.

The Nano-emulsion, besides possessing removal efficiency slightly better than the micro-emulsion one, becomes more advantageous due to being a system rich in water, having a minimum percentage of oil phase and surfactant and co-surfactant, being more viable economically and environmentally. Analyzing the technology of both systems, the slight improvement in efficiency of the Nano-emulsion should also be attributed to its small particle diameter, about $1 \mathrm{~nm}$, which facilitates their penetration into the pores of the soil.

Despite being diluted 10 times more than the micro-emulsion system, the Nano-emulsion's performance was not compromised when compared to the micro-emulsion one, with a removal percentage of $88 \%$ (Nano-emulsion) and $86 \%$ (micro-emulsion) injection volume to $3,000 \mathrm{~mL}$ (Table 2). This can be attributed to the similarity in values of surface tension of the condensed vapor of these systems (Table 1).

The results of this paper when compared with those in the literature $[1,7,10,11,26,27]$ have a better performance, since the paper described above, use wash columns or surfactants in need of treatment by bioremediation a longer treatment time. While the methodology employed in this paper covers a larger area of treatment and still need a shorter time to treat this larger area resulting in a similar percentage of removal.

\section{Conclusion}

This study shows that the steam injection of Nano-emulsion was more efficient and advantageous than the injections of water vapor, micro-emulsion and surfactant solutions due to the combination of these factors:

- Reduction of surface tension associated with the oil phase and particle diameter size;

- Desorption of diesel caused by micelle encapsulation, and by the thermal energy supplied by steam which, in part, helped volatilize the diesel, and reduce its viscosity, facilitating their desorption from the soil.

This work showed for the first time the use of steam surfactant systems in aqueous solution and in micro and Nano-emulsions as an alternative for the remediation of soils contaminated by diesel.

\section{Acknowledgment}

The authors of this paper thank the PRH-ANP 14 for financial assistance to conduct this research and for the award of a PhD scholarship.

\section{References}

1. Lu L, Yazdi H, Jin S, Zuo Y, et al. (2014) Enhanced bioremediation of hydrocarbon-contaminated soil using pilot-scale bioelectrochemical systems, Journal of Hazardous Materials 274: 8-15.

2. Ramalho AMZ, Aquino Sobrinho HL, Anjos RB, Castro Dantas TN, et al. (2014) Study of contamination by benzene due diesel and gasoline leaks at a gas station in Natal / Brazil., Internacional Journal of Engineering \& Technology IJET-IJENS 4: 49-54.
3. Paria S (2008) Surfactant-enhanced remediation of organic contaminated soi and water, Advances in Colloid and Interface Science 138: 24-58.

4. Enviromental Protection Agency United States (2012) Remediantion/Cleanup Technologies.

5. Coulon F, Brassington KJ, Bazin R, Linnet PE, et al. (2012) Effect of fertilizer formulation and bioaugmentation on biodegradation and leaching of crude oils and refined products in soils, Environmental Technology 33: 1879-1893.

6. Liu PWG, Chang TC, Whang LM, Kao CH, et al. (2011) Bioremediation of petroleum hydrocarbon contaminated soil: Effects of strategies and microbial community shift, International Biodeterioration \& Biodegradation 65: 1119-1127.

7. Liu PWG, Chang TC, Chen CH, Wang MZ, et al. (2014) Bioaugmentation efficiency investigation on soil organic matters and microbial community shift of diesel-contaminated soils, International Biodeterioration \& Biodegradation.

8. Liu PWG, Wang SY, Huang SG and Wang MZ (2012) Effects of soil organic matter and ageing on remediation of diesel-contaminated soil, Environmental Technology 33: 2661-2672.

9. Mukherjee AK and Bordoloi NK (2011) Bioremediation and reclamation of soi contaminated with petroleum oil hydrocarbons by exogenously 379 seeded bacterial consortium: a pilot-scale study, Environmental Science and Pollution Research 18: 471-478.

10. Whang LM, Liu PWG, Ma CC and Cheng SS (2009) Application of rhamnolipid and surfactin for enhanced diesel biodegradation - Effects of $\mathrm{pH}$ and ammonium addition, Journal of Hazardous Materials 164: 1045-1050.

11. Whang LM, Liu PWG, Ma CC and Cheng SS (2008)Application of biosurfactants, rhamnolipid, and surfactin, for enhanced biodegradation of diesel-contaminated water and soil, Journal of Hazardous Materials 151: 155-163.

12. Mittal KL (1979) Solution Chemistry of Surfactants. Plenum Press New York

13. Zhang W and Lo IMC (2007) Chemical-Enhanced Washing for Remediation of Soils Contaminated with Marine Diesel Fuel in the Presence/Absence of $\mathrm{Pb}$, Enviromental Engineering 133: 548-555.

14. Lange KR (1999) Surfactants a Pratical Handbok. Hanser Publishers Munich, Germany.

15. Laha S, Tansel B and Ussawarujikulchai A (2009) Surfactant-soil interactions during surfactant-amended remediation of contaminated soils by hydrophobic organic compounds: A review, Journal of Environmental Management 90: 95100

16. Lee DH, Cody RD, Kim DJ and Choi S (2002) Effect of soil texture on surfactantbased remediation of hydrophobic organic-contaminated soil, Environment International 27: 681-688.

17. Dwarakanath V, Kostarelos K, Pope GA, Shotts D, et al. (1999) Anionic surfactant remediation of soil columns contaminated by nonaqueous phase liquids, Journal of Contaminant Hydrology 38: 465-488.

18. Owsianiak M, Chrzanowski Ł, Szulc A, Staniewski J, et al. (2008) Biodegradation of diesel/biodiesel blends by a consortium of hydrocarbon degraders: Effect of the type of blend and the addition of biosurfactants, Bioresour. Technol. 100 1497-1500.

19. Urum K, Grigson S, Pekdemir T, McMenamy S (2006) A comparison of the efficiency of different surfactants for removal of crude oil from contaminated soils, Chemosphere 62: 1403-1410.

20. Chu W and Kwan CY (2003) Remediation of contaminated soil by a solvent surfactant system, Chemosphere 53: 9-15.

21. Couto HJB, Massarani G, Biscaia Jr EC, Sant'Anna Jr GL (2009) Remediation of sandy soils using surfactant solutions and foams, Journal of Hazardous Materials 164: 1325-1334.

22. Dantas TNC, Moura MCPA, Dantas Neto AA, Barros Neto EL (2007) The use of microemulsion and flushing solutions to remediate diesel-polluted soil, Brazilian Journal of Petroleum and Gas 1: 26-33.

23. Darban AK, Ganjudust H, Salehian E (2010) Factors Affecting Site Remediation of Diesel Contaminated Soils Using Surfactants. Enviroment, Ecosystems and Sustainaible Development: 6th WSEAS International Conference on Energy.

24. Duffield AR, Ramamurthy RS, Campanelli JR (2003) Surfactant Enhanced Mobilization of Mineral Oil within Porous Media, Water, Air, and Soil Pollution 143: 111-122. 
Citation: Bezerril RH, de Souza TTC, Ramalho AMZ, da Silva DR, Dantas TNC (2014) Comparative Study of Injection Systems in Vapor Phase in the Remediation of Soils Contaminated by Diesel. J Pet Environ Biotechnol 5: 184. doi:10.4172/2157-7463.100018

Page 6 of 6

25. Gupta MK, Srivastava RK, Singh AK (2010) Bench scale treatability studies of contaminated soil using soil washing technique. , E-journal of Chemistry 7 : 73-80.

26. Khalladi R, Benhabiles O, Bentahar F, Moulai-Mostefa N (2009) Surfactant remediation of diesel fuel polluted soil, Journal of Hazardous Materials 164 : 1179-1184.

27. Salehian E, Khodadadi A, Hosseini B (2012) Remediation of diesel contaminated soils using surfactants: coulumn study, American Journal Enviromental Sciences 8: 352-359.

28. Gradzielski M (2008) Recent developments in the characterisation of microemulsions, Current Opinion in Colloid \& Interface Science 13: 263-269.

29. Holmberg K, Jonsson B, Kronberg B, Lindaman B (2002) Surfactantes and polymers in aqueous solution. 2, John Wiley\& Sons, Ltd. England.

30. Rossi CGFT, Dantas TNC, Dantas Neto AA, Maciel MAM (2006) Tensoativos: uma abordagem básica e perspectivas para aplicabilidade industria, Rev Univ Rural Sér Ci Exatas e da Terra 25: 59-71.

31. Klang V, Matsko N, Valenta C, Hofer F (2012) Electron microscopy of nanoemulsions: An essential tool for characterisation and stability assessment, Micron 43: 85-103.

32. Mittal KL, Shah DO (2002) Adsorption and aggregation of surfactants in solution. Marcel Dekker, Inc New York.
33. Chu W (2003) Remediation of contaminated soils by surfactant - aided soil washing., Journal of Hazardous, Toxic, and Radioactive Waste 7: 19-24

34. Thomas JE (2001) Fundamentos de engenharia de petróleo. 2, Interciência Rio de Janeiro, RJ.

35. Oxiteno.

36. Gomes DAA (2009) Applications of microemulsions in the solubilization of heavy oil fractions. Dissertation (Masters in Chemical Engineering). Federal University of Rio Grande do Norte, Natal/Brazil.

37. Pereira R, Guimarães Junior JA (2011) Capacidade de infiltração das dunas de Natal, capital do RN. . XIX Simpósio Brasileiro de Recursos Hídricos.

38. Souza TTC (2013) Nanoemulsions applied to enhanced oil recovery. Chemica Engineering, Federal University of Rio Grande do Norte, Brazil.

39. Dantas TNC, Dantas Neto AA, Rossi CGFT, Gomes DAA, et al. (2010) Use of micromeulsion systems in the solubilization of petroleum heavy fractions for the prevention of oil sludge waste formation., Energy \& Fuels 24: 2312-2319.

40. Nascimento AR, Ziolli RL, Ararun Jr JTI, Pires CS, et al. (2008) Validation of method for the determination of TPH (Total Petroleum Hydrocarbon) by infrared detection, Eclética Química 33: 35-42. 